\title{
Cloud Computing Technology Model for Teaching and Learning of ICT
}

\author{
Peter Appiahene \\ University of Energy and \\ Natural Resources-Ghana
}

\author{
Bryce Yaw Kesse \\ Berekum College of Education
}

\author{
Christopher Bombie \\ Ninfaakang \\ University of Energy and \\ Natural Resources-Ghana
}

\begin{abstract}
Information and communication Technology (ICT) is basically making use of ICT tool to store and retrieves information. It plays an important role in growing and maintaining country's economic growth. Currently, the old system of classroom teaching and learning of ICT is changing and students in Ghana are becoming more technology oriented. Therefore, in this changing learning environment, it's important one thinks of the latest technologies to incorporate in the teaching and learning of ICT. One of the latest technologies prevailing nowadays is cloud computing. By sharing IT services as platform-based, software-based and infrastructure-based in the cloud, educational institutions in Ghana can now out-source non-core services and better concentrate on offering students, teachers, faculty and other staff the essential tools to help them succeed.
\end{abstract}

This paper looks at how Cloud Computing can be applied in the study of ICT and also focuses on the role of cloud computing on the study of ICT in the Ghanaian educational system. It also looks at how one can provide quality and affordable ICT education by using cloud computing technology. A study of the previous system without cloud computing technology was considered and a new model of teaching ICT with help of cloud computing technology has been proposed.

An extensive review and analysis of the existing literature and models were considered and a new model was designed and piloted. Our research shows that for the past decades, most public and private educational institutions in Ghana are making grant strides in the development of curriculum for teaching ICT. The model designed was found to be effective and useful for the teaching and learning of ICT and its related subjects. Our research also shows that a good number of tertiary institution both private and public now offer various IT and its related degree and diploma programs. The Ghana Education Service now runs ICT at basic and second cycle levels as subjects.

\section{General Terms}

Cloud Computing Technology and Education.

\section{Keywords}

Information and Communication Technology Education, Cloud Computing Technology, SaaS, PaaS, IaaS, CCT4ICT.

\section{INTRODUCTION}

There has been numerous publicity to the various educational institutions to develop and run ICT and its related programs. Parents are encouraged to send their wards to schools and colleges that run ICT and its related programs. There have been various models to promote ICT education in Ghana but lack of facilities, good teachers, and lack of latest books and labs facilities seriously affects their results and practical skills as ICT education is purely practically oriented and thus discourages them to continue their education. One of the biggest challenges that the government faces in providing education is the lack of infrastructure and if available then maintenance of that infrastructure and other issues in procuring and maintaining a wide range of hardware and software[1].

With this challenge, IT education would be one of the most affected as it is purely practically oriented. Cloud computing can provide solutions to these challenges and reduced it to some extent. Thus by implementing cloud computing technology, countries can overcome most of these challenges and also maintain a centralized system where all stakeholders can check the ICT education system from each and every aspect and continue to monitor and guide the system. They can not only check the needs of the ICT institutions, but also ensure that quality IT education is provided to every student and also his attendance, class performance and others attributes can be effectively monitored and maintained without worrying for the infrastructure issues.

The Cloud Computing Technology (CCT) helps to ensure that students, faculty, parents and other staff have on-demand access to critical information using any device from anywhere, at any time. Both public and private institutions that offer IT education can use the CCT to deliver better services, even with limited resources.

\section{INFORMATION TECHNOLOGY EDUCATION IN GHANA}

ICT (Information and communications technology), is a broad term that includes any communication device or application, encompassing: radio, television, cellular phones, computer and network hardware and software, satellite systems and so on [2]-[4].The term also ICT includes computers, computer networking (the Internet and intranet), peripheral devices and multimedia, and the range of assistive technologies available for children with Special Educational Needs[1].

For the purpose of this work, the term Information and Communication Technology (ICT) and Information Technology (IT) would be used interchangeably. CT as an elective subject in Senior High Schools (SHS) can be offered as Computer

Science/Studies (CS) or Information Technology (IT). These two course have many joint features but they are distinctive subjects, each with their own drive, and neither can fully auxiliary for the other[5].

Schools and colleges therefore decide for the one or the other or both in their subject packages, depending on their country's needs .With IT been an applied field of study, CS has scientific, mathematical and practical dimensions.

The use of ICT to improve productivity at work has increased over the years, and as such it is paramount that every tom, 
dick and harry attains a higher level in computer literacy. Part of the task of educational institutions is to produce workforceready graduates who can, among other things, manipulate and analyze raw data, critically evaluate information, and operate hardware and software[6].

In Ghana, ICT as a core subject is normally taught at all levels of the school educational system. Some senior high schools, technical and vocational schools offer ICT as an elective subject.

Some higher institutions, both public and private also offer ICT as well as its-related courses to their students at the bachelors' level, masters' level, and also $\mathrm{PhD}$ level. For example, University of Energy and Natural Resources, University of Ghana offer IT and Computer science even up to the $\mathrm{PhD}$ level, Catholic University College, Christian Service University College and Kwame Nkrumah University of Science and Technology also offer ICT and its related programs etc. There are also some institutions such as NIIT and IPMC also offer ICT education, as well as providing ICT solutions and services to their clients in Ghana.

ICT education in Ghana is not without issues. Some of these issues are: Lack of access to appropriate technologies. In most places in Ghana teachers teach students ICT without having access to any technology for proper demonstration. This is mostly due to cost constraints, Lack of technical knowledge, Lack of adequate time for planning lessons. Policy efforts should therefore be directed at using cheap ICTs to facilitate teaching and learning within the educational system and to promote e-learning as well as life-long learning within the population at large[7].

\section{CONCEPTUALISED FRAMEWORK}

Cloud computing is receiving a great deal of attention, both in publications and among users, from individuals at home to the government. Cloud computing is a subscription-based service where one can obtain networked storage space and computer resources[7]-[11]. When one save pictures, CVs, copies of assignment in emails and even use google classroom platform instead of home computer, then "cloud computing technology (CCT)" service is been offered. If a lecturer want to use for example, an online learning tutorials to reach out to students instead of using a computer presentation in the classroom, then that online presentation service is a "CCT" service.

Cloud Computing Technology, CCT refers to the carriage of computing resources and services over the global internationally recognized network popularly known as internet. Instead of keeping data on one's own storage device or installing an application on one's own home computer, you use an infrastructure /service over the Internet, at another locality, to store your information or use its applications[12][16].

Cloud Computing provides environments to enable resource sharing in terms of scalable infrastructures, middleware and application development platforms, and value-added business applications. These resources include the following; Infrastructure resources, Software resources, Application resources, Business processes[17].Cloud Computing has become a significant technology trend, and many experts expect the cloud computing will reshape Information Technology (IT) processes and the IT marketplace. With the cloud computing technology, users uses a variety of devices, including PCs, laptops, smartphones, and PDA's to access programs, storage and application-development platforms over the internet, via services offered by cloud computing providers.

Advantages of the cloud computing technology include cost savings, high availability and easy scalability. Cloud options range from everyday services, such as email, calendaring and collaboration tools that members can collaborate online[18]. System Administrators can bring new services and computing capacity online quickly while managing costs as operational expenses.

Cloud computing is as computing model based on networks, especially based on the Internet, whose task is to ensure that users can simply use the computing resources on demand and pay money according to their usage by a metering pattern. Therefore, a new business model is being created where the services it provides are becoming computing resources.

\subsection{The Cloud Computing Technology \\ (CCT) Service Models}

Cloud computing Technology services are generally regarded as falling into three separate categories, Infrastructure as a Service (IaaS)-The IT infrastructures like processing, storage, networks and other fundamental computing resources can be used by the consumers as a service. In order to integrate/decompose physical resources IaaS uses Virtualization extensively. Platform as a Service (PaaS)-To develop cloud services and applications PaaS provides a development platform supporting the full "Software Lifecycle". PaaS requires programming environment, tools, configuration management etc., to support the application hosting environment and Software as a Service (SaaS)-The Software usage is provided to a consumer as a Service. Based on the demand the consumer can choose his software to use. Cloud providers release their applications on a hosting environment, which can be accessed through networks from various clients like web browser, PDA, etc., by the application users[17].

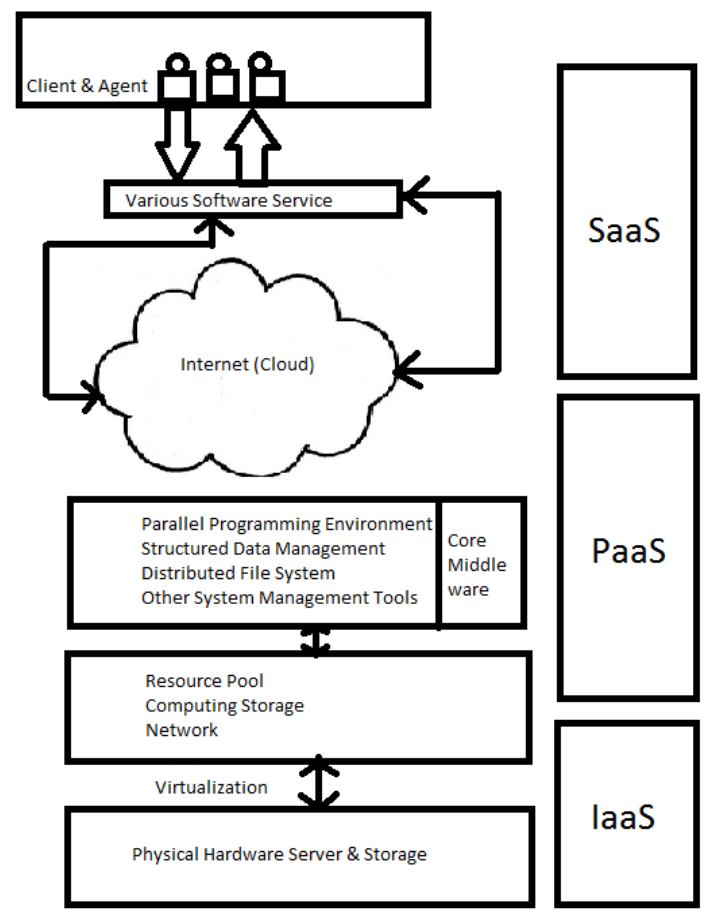

Figure 1.The Service Models of CCT adopted from Lakshminarayanan et al, 2010 


\subsection{Cloud Computing Technology for ICT (CCT4ICT) model in Educational system}

Most educational institutions have become highly dependent on information and communication technology tools to provide solutions and also service their requirements. These services and solutions are progressively provided using Internet Services to both teaching non-teaching staff and students and accessed using web browsers. The services are presented are not cheaply or not freely to education, often with most of these educational institutions spend a lot on the various resources in order to provide quality services to their users

The society are most likely to face a future where the majority of educational services will be hosted in the cloud and institutions no longer host their own data centers with expensive hardware, power bills, staff salaries and computing resources .This paper brief has analyzed some of the emerging benefits and challenges of Cloud Computing Technology (CCT) for the study of IT in the educational sector. In most of the government schools and colleges in Ghana IT plays very small role in the teaching and learning of ICT. Most of the work is done manually from attendance to classroom teaching and even to examination system.

Cloud Computing Technology for ICT education model (CCT4ICT) can provide solutions for the above mentioned problems in the study of ICT in our educational system. CCT4ICT enables users to control and access data via the Internet. The main users of a typical CCT4ICT include ICT students, ICT Faculty members, administrative staff, Examination Branch and Admission Branch.
All the main users of the institution are connected to the CCT. Separate logins are provided for all the users for their respective work. ICT lecturers can upload their class Tutorials, assignments, and tests on the CCT server which students will be able to access all the teaching material provided by the teachers via Internet using computers and other electronic devices both at home and in schools irrespective of their location college. The CCT4ICT will make it possible for lecturers to identify problem areas in which students tend to make mistakes, by analyzing students' study records. In doing so, it will also allow lecturers/teachers to improve teaching materials and methodologies.

This will not only make it possible for students to use online teaching materials during class but they will also be able to access these materials at home, using them to prepare for and review lessons. Utilization of CCT4ICT will reduce the cost of operation because servers and learning materials are shared with other colleges. Lecturers who normally travels outside for seminars, conferences and other academic programs can still get in touch with their students at very affordable price using CCT4ICT education model.

In the traditional deployment model, all Information Technology resources are housed and managed in-house normally by ICT experts. Many aspects of these services, solutions and tools can be migrated to the cloud and consumed directly over the internet either as fully functional applications (SaaS), development platforms (PaaS) or raw computing resources (IaaS).Figure 3 shows how CCT can be integrated with the different learning approaches of ICT education.

This model was adopted from NCCA: 2004a but has now be incorporated with CCT.

\section{The proposed Model by Authors}

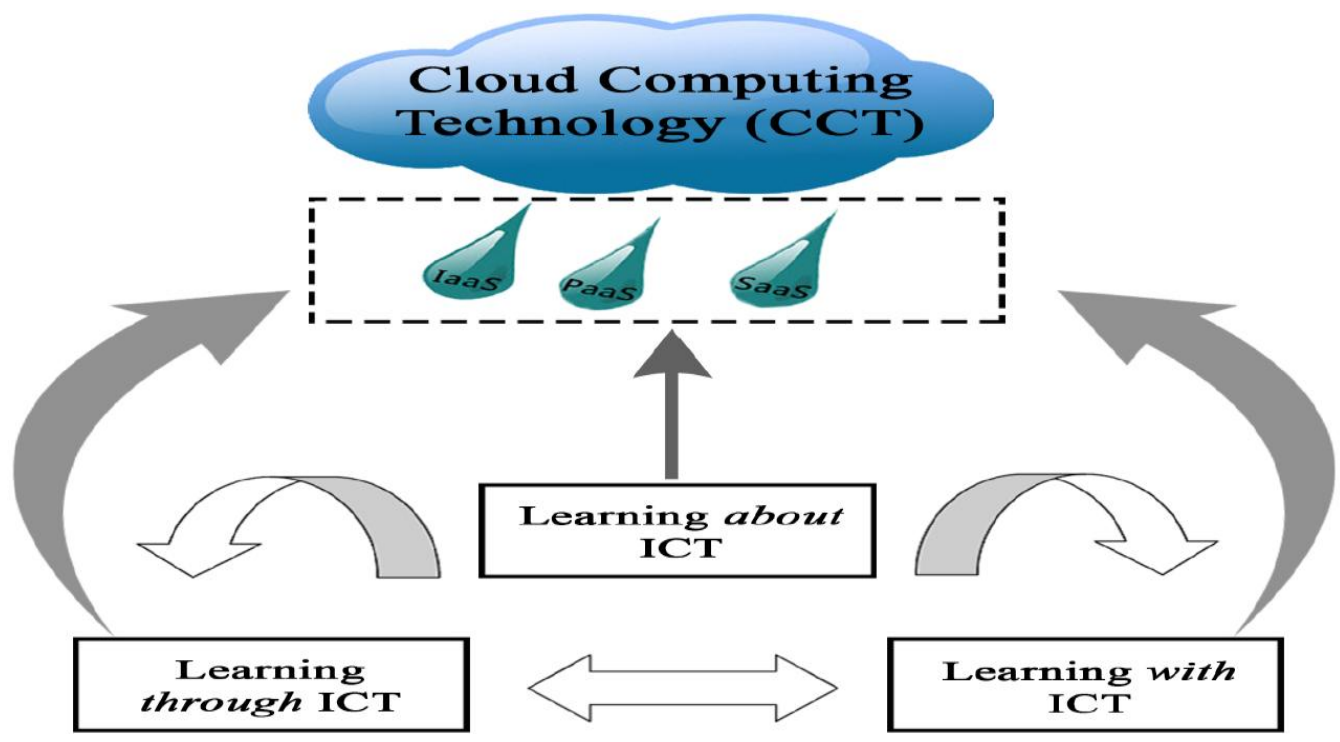

Fig 3: CCT4ICT education model designed by authors

\section{IMPORTNACE OF CCT4ICT MODEL FOR THE TEACHING AND LEARNING OF ICT}

- Independent Learning style: The CCT4ICT model will affords student greater opportunity to choice the best learning style and also at their own pace. Using an ICT device, students can access a wide array of resources and software tools that suit their learning styles and interests.

- No Extra Infrastructure: Colleges and governments are now free to focus on their goals that is making more research facilities available to the students and making the environment global in 
spite wasting time on worrying about the buildings, labs, teachers etc.

- No more expensive textbooks and Infrastructure. This is not secret that higher education-level textbooks and other materials are expensive. Even in some cases they are not easily to come by .The cost of textbooks and other ICT learning materials has outpaced the cost of virtually everything else in education, including tuition. As a result, many students cannot afford them. Cloud Computing Technology-based textbooks can solve this problem as digital content is significantly less expensive than printed content and most of them are also free. This situation therefore gives a level playing field all ICT students in both developing and developed countries.

- No more outdated learning materials. About two decades ago in Ghana where access to internet was major challenge, most ICT students were using outdated materials and even software tool. The pace at which the ICTs are moving is very fast and institutions in developing country like Ghana are normally lag behind. The problem of expensive textbooks implies that many of the materials students are using are outdated. Our research shows that about two decades ago in Ghana the average ICT book schools is seven to eleven years old. CCT-based ICT materials are easy to bring up-todate in real time so that students always have access to the most recent learning resources.

- No expensive software required. One of the main advantages of CCT-based computing is the software-as-a-service (SaaS) model. Many software programs are now open source and readily available either free or on a low-cost subscription basis, which substantially lowers the cost of essential applications for students. For instance, instead of purchasing a single Microsoft Office application student license for GH800, students and their families can purchase a CCT-based subscription for five laptops and five smartphones devices for only GH 50 per month. Some of them such as Google Docs are even free. Institutions can also store big data by using SaaS applications-traditional Education management systems can cost upwards of Gh200, 000 or even more, but CCT-based learning management systems such as Google Classroom are less or free.

- No boundaries to students learning environment. CCT opens up a world of new options for students, especially those who are not assisted well by traditional education systems. For instance until the inception of online education, the options for the old who didn't have formal education were very limited but now they can earn their diploma or degree online at any institution so far as they offer that service.

In these and other things, CCT is not only reducing costs, but also creating an environment where ICT students can have access to high-quality education and resources. Whether you are an administrator, a teacher, a student, or the parent of a student, now is a great time to explore how CCT-based applications can benefit you, you're children, and your school.

\section{ISSUES IN THE USAGE OF THE CCT4ICT MODEL}

CCT challenges have always been there. Companies and institutions are gradually aware of the business value that CCT brings and are taking steps towards conversion to the cloud. A smooth conversion involves an exhaustive understanding of the benefits as well as challenges involved. Like any new technology, the adoption of CCT4ICT model is not free from issues. Some of the most important challenges are as follows.

- Security and Privacy: The main challenge to cloud computing is how it addresses the security and privacy concerns of institutions adopting it. The fact that the valuable instructions data such us students examination results will reside outside the corporate firewall raises serious security concerns. Hacking and various attacks to CCT infrastructure would affect multiple clients even if only one site is compromise. These risks can be lessened by using advance security applications, high quality encrypted file systems, data loss software, and buying security hardware to track unusual behavior across servers.

- Service Delivery and Billing: It is not simple to assess the costs involved due to the on-demand nature of the services. Accounting and valuation of the cost will be very difficult unless the provider has some decent and equivalent benchmarks to offer. The service-level agreements (SLAs) of the provider are not adequate to guarantee the availability and scalability. Institutions will be reluctant to switch to CCT without a strong service quality guarantee.

- Interoperability and Portability: Institutions should have the control of migrating in and out of the CCT and switching providers whenever the need arises. CCT services should have the capability to integrate smoothly with the existing ICT tools in the institutions.

- Reliability and Availability: CCT service providers still lack round-the-clock service; this results in frequent outages. In Ghana the unreliable power supply popularly known as Dumsor (pronounced "doom-sore" or more appropriately dum so, "off and on" is a popular Ghanaian term used to describe persistent, irregular and unpredictable electric power outages) for example can affect the reliability and availability of the CCT. It is important to monitor the service being provided using internal or third-party tools. It is vital to have plans to supervise usage, SLAs, performance, robustness, and business dependency of these services.

- Performance and Bandwidth Cost: Institutions can save money on hardware and other software but they have to spend more for the bandwidth. This can be a lower cost for smaller applications but can be expressively high for the data-intensive applications. Delivering intensive and multifaceted data over the network requires enough and sufficient bandwidth. Because of this, many institution in Ghana are waiting for a reduced cost before using the CCT. 
All these challenges should not be considered as road blocks in the pursuit of CCT. It is rather important to give serious attention to these issues and the possible ways out before adopting the technology.

\section{CONCLUSIONS}

The CCT allows one to access work anywhere, anytime and share. It helps one from needing a particular machine to access a file or an application like a word processor or spreadsheet program. In this paper a cloud education model called CCT4ICT was introduced and how it is beneficial for students, faculty and the educational institutes for providing quality ICT education. Challenges such as cost, security and other issues were also considered. Future assessment of the model would also be considered

\section{ACKNOWLEDGMENTS}

Our thanks goes to Prof.F.A.Adekoya who supervise and read through our work.

\section{REFERENCES}

[1] P. Appiahene, F. L. Boateng, A. Floyd-Hackman, Lord Onwona-Agyeman Anthony, and O. Micheal, "Using Information and Communication Technology ( Ict ) To Predict Teachers Productivity," vol. 2, no. 2, pp. 348355, 2014.

[2] S. Majumdar, "Emerging Trends in ICT for Education \& Training," Unevoc.Unesco.Org, 2006.

[3] S. Noor-Ul-Amin, "An Effective use of ICT for Education and Learning by Drawing on Worldwide Knowledge , Research , and Experience: ICT as a Change Agent for Education," no. 1999, pp. 1-13, 2013.

[4] F. Mikre, "The Roles of Information Communication Technologies in Education Review Article with Emphasis to the Computer and Internet," African Journals Online, vol. 6, no. 2, 2011.

[5] A. Verno, D. Carter, R. Cutler, M. Hutton, L. Pitt, and A. Tucker, "A Model Curriculum for K-12 Computer Science* Level 2 Objectives and Outlines," Comput. Mach., 2003.

[6] S. Patti, "ICT as Core and as Elective Subject: Issues to Consider," pp. 1-13, 2006.
[7] a P. Statement, F. O. R. The, R. Of, T. H. E. Vision, T. O. Transform, a N. I. K. Society, T. T. H. E. Development, and T. H. E. Economy, "Republic of Ghana THE GHANA ICT FOR ACCELERATED DEVELOPMENT,” Econ. Soc., 2003.

[8] A. Huth and J. Cebula, "The basics of cloud computing," United States Comput., pp. 1-4, 2011.

[9] LuitInfotech 2014, "What Is Cloud Computing ?," 2014.

[10] I. T. Education and T. Ges, "Cloud Computing Technology ( CCT ) and Information Technology Education in Ghana," pp. 1-8, 2014.

[11] Dialogic Corporation, "Introduction to Cloud Computing - 12023-cloud-computing-wp.pdf,"p. 8, 2010.

[12] "Cloud Computing Technology model for Teaching and Learning of ICT," pp. 1-11, 2014.

[13] "Topic: Cloud Computing Architecture Paper survey • CCOA : Cloud Computing Open Architecture."

[14] E. G. Report, “C Loud C Omputing,” 2010.

[15] National Institute of Standards and Technology, "The NIST Definition of Cloud Computing (SP 800-145)," vol. 145, no. 20 Nov 2012, p. 6028, 2011.

[16] A. M. Areshey, "Applications of Cloud Computing in Education," vol. 6, no. 4, pp. 26-33, 2015.

[17] R. Lakshminarayanan, B. Kumar, and M. Raju, "Cloud Computing Benefits for Educational Institutions," Second Int. Conf. Omani Soc. Educ. Technol., vol. 8, no. 2, pp. 104-112, 2013.

[18] D. Wu, P. Hugenholtz, K. Mavromatis, R. Pukall, E. Dalin, N. N. Ivanova, V. Kunin, L. Goodwin, M. Wu, B. J. Tindall, S. D. Hooper, A. Pati, A. Lykidis, S. Spring, I. J. Anderson, P. D'haeseleer, A. Zemla, M. Singer, A. Lapidus, M. Nolan, A. Copeland, C. Han, F. Chen, J.-F. Cheng, S. Lucas, C. Kerfeld, E. Lang, S. Gronow, P. Chain, D. Bruce, E. M. Rubin, N. C. Kyrpides, H.-P. Klenk, and J. a Eisen, "CLOUD COMPUTING - An Overview An Overview," White Pap., vol. 462, no. 7276, pp. 1-5, 2009. 